\title{
Short case reports
}

\section{Uncommon complications of early syphilis Hepatitis, periostitis, iritis with papillitis, and meningitis}

\author{
J. D. J. PARKER \\ Consultant Venereologist, Tottenham Group of Hospitals, and Chief Assistant in Venereology, \\ St. Bartholomew's Hospital, London
}

For over 20 years Great Britain has experienced an incidence of syphilis which is remarkably low compared with that in many countries of comparable living standards, and the less frequent complications of secondary syphilis of the pre-war era have become uncommon to the point of rarity. Four cases of early syphilis with unusual manifestations seen at St. Bartholomew's Hospital in recent years are described.

\section{Case 1. Hepatitis}

A homosexual publican aged 43 years was admitted to the medical ward in July, 1965; he had developed anorexia and skin irritation 2 weeks previously. He noticed that his urine was dark, and a few days later he became jaundiced. He had no abdominal pain, but he vomited occasionally and had lost some weight. There was no recent history of ingestion of drugs, treatment by injection or transfusion, or contact with chemicals, nor had he been abroad. He admitted to regular heavy consumption of spirits. In 1952, when he was under investigation for a suspected prolapsed intervertebral disc, the Wassermann reaction had proved negative.

On admission to hospital he was deeply jaundiced, but no other abnormal clinical signs were noted; there was no enlargement of liver, spleen, or lymphatic glands, and no pyrexia.

\section{Examination}

He was seen by a venereologist 2 weeks later because by this time he had developed a generalized macular rash with annular lesions on the palms and soles, and the cervical and inguinal glands were enlarged. There were no penile or perianal lesions. No treponemes were seen by darkfield examination of scrapings from the skin lesions, but the serum tests for syphilis proved positive as follows: CWR +, VDRL + 1/32, RPCFT +, FTA-ABS +, TPI + .

\section{Laboratory investigations}

Erythrocyte sedimentation rate $70 \mathrm{~mm}$. in the first hour; blood sugar $320 \mathrm{mg}$. per cent.; serum cholesterol $635 \mathrm{mg}$. per cent.; serum bilirubin $\mathbf{9 . 4} \mathrm{mg}$. per cent.; direct Van den Berg test positive; alkaline phosphatase 98 K.A. units; serum albumin $3.2 \mathrm{~g}$. per cent.; SGOT 84 units; floc-

Received for publication February 17, 1971. culation tests slightly abnormal; cerebrospinal fluid normal.

The liver function tests suggested a predominantly obstructive jaundice with hepatocellular damage. A needle biopsy of the liver showed only slight cellular infiltration and some cholestasis. The portal tracts were oedematous, and there was cellular infiltration and also proliferation of the bile ducts (Figs 1 and 2).

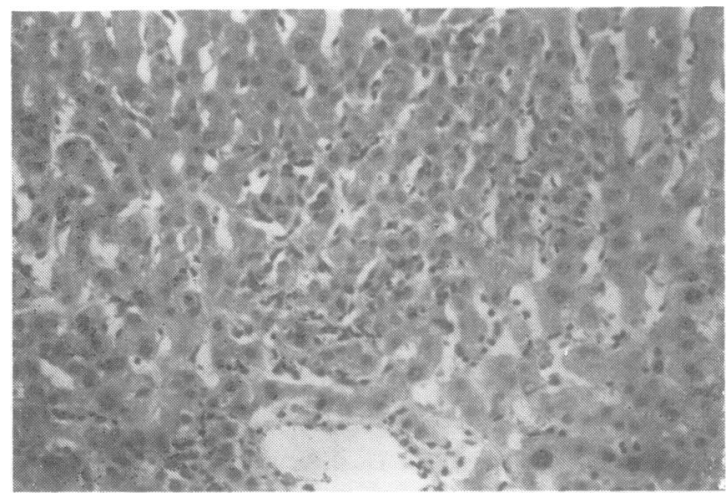

FIG. 1 Case 1. Low-power photomicrograph of liver parenchyma, showing slight cellular infiltration and cholestasis

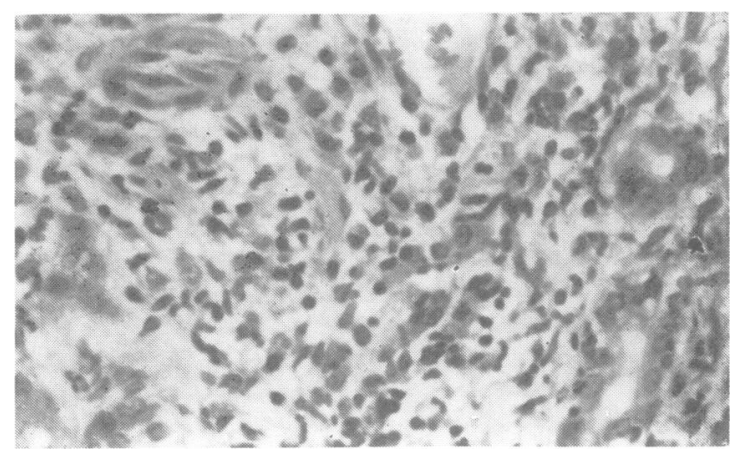

FIG. 2 Case 1. High-power photomicrograph of portal tract, showing infiltration with round cells, plasma cells and fibroblasts, and bile duct proliferation 
A Warthin Starry stain for spirochaetes was negative. A cholangiogram subsequently showed poor excretion but no evidence of bile duct obstruction.

\section{Treatment}

Daily injections of penicillin were given for a total of 15 days, and the jaundice began to subside during the course of penicillin. His previously unsuspected diabetes was treated at first with insulin and was eventually controlled with tolbutamide. The standard serological tests for syphilis became negative by December, 1965, and had remained so when he was last seen in 1967; the FTA-ABS was still positive.

\section{Comment}

Hepatitis due to early syphilis is uncommon; it has received scanty attention in the literature, and few histological studies have been reported. Hahn (1943) estimated the frequency of this complication as 0.24 per cent., and from reports in the preceding 50 years he could find only seven acceptable cases in which liver tissue was available either at laparotomy or post mortem. In five cases diffuse miliary interacinar granulomatous lesions were found, and in the other two there was diffuse round cell infiltration of connective tissue with no granulomatous nodules. Most of the patients had been given arsenical compounds and this might have modified the histological appearances.

Diagnostic criteria for early syphilitic hepatitis are given as jaundice coincident with untreated early syphilitic lesions taking a benign course and showing a rapid response to antisyphilitic treatment. According to Schiff (1963) hepatic involvement in early syphilis is suggested by diffuse liver tenderness or enlargement, less commonly by jaundice, and reduction in bromsulphalein excretion with depression of other liver function test results is usual. Typical histological changes are said to consist of small interacinar granulomata and diffuse inflammation of reticulo-endothelial structures. Sherlock (1968) describes similar granulomatous lesions, but also states that diffuse hepatitis with mild jaundice can occur in secondary syphilis. She considers however that most liver disease in syphilis is due to viral hepatitis transmitted by syringes.

The case described does not fit well into any recognized pattern but there was no satisfactory explanation for the hepatitis other than the association with syphilis. The histological findings did not support a diagnosis of viral hepatitis, and there was more inflammatory reaction than would be expected in cholestatic jaundice. There was no histological evidence of alcoholic damage. Haemochromatosis (suggested by the coincident diabetes) and extrahepatic obstruction can be excluded because of the clinical course.

\section{Case 2. Periostitis}

$A$ bisexual actor aged 35 years, who attended the clinic at St. Bartholomew's Hospital in September, 1969, complained of pain in both tibiae with paraesthesia of the ankles of 3 weeks' duration. Some recent bruises were more persistent and tender than he would have expected.

\section{History}

He had previously attended the clinic at St. Mary's
Hospital, where he had been treated in 1960 for secondary syphilis. The serological test results had reverted to negative after treatment, and had remained so until 1967. In January, 1968, he developed seropositive primary syphilis, and a course of penicillin was prescribed. After six injections he developed urticaria, and treatment was continued with tetracycline $500 \mathrm{mg}$. four times a day for one week. In September, 1968, the Wassermann reaction was weakly positive, and when he next attended in July, 1969, it was positive at a titre of 1 in 20 . He was not seen again until he attended St. Bartholomew's 2 months later.

\section{Examination}

There was a hard flat tender swelling 3 " long below the left tibial tuberosity, and a similar swelling above the right medial malleolus. There were no other abnormal findings. The results of serological tests for syphilis were positive as follows:

CWR +, VDRL + 1/32, RPCFT +, FTA-ABS +.

\section{Laboratory investigations}

Erythrocyte sedimentation rate $13 \mathrm{~mm} . / 1 \mathrm{st} \mathrm{hr}$; cerebrospinal fluid no abnormality; $X$ rays (October 23 ) showed periostial reaction over the upper part of the left tibia and the lower part of the right tibia (Fig. 3).

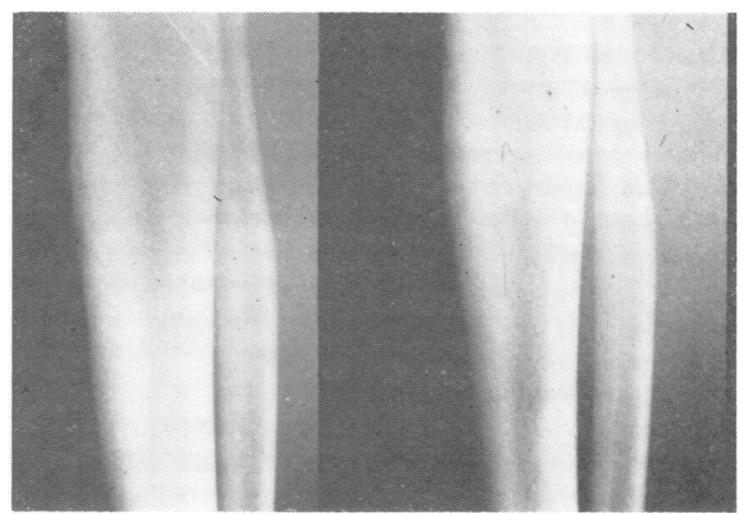

FIG. 3 Case 2. Radiograph of left tibia, showing appearance before (October, 1969) and after (Fanuary, 1970) treatment

He was admitted for treatment, and because of the history of allergy to penicillin was given injections of cephaloridine $500 \mathrm{mg}$. four times a day for 2 weeks. After the first two injections the lesions increased in size and became more tender, but thereafter the symptoms subsided. In January, 1970, $X$ rays showed resolution of the periostitis (Fig. 4, overleaf). Serological tests in April, 1970 , showed a fall in VDRL titre to 1 in 8 , and in October, 1970, to 1 in 2.

\section{Comment}

Although skeletal pain is not uncommon in early acquired syphilis, it is unusual to find objective evidence of periostial or osseous involvement. Reynolds and Wassermann (1942) described several cases of syphilis with osteolyt:c 


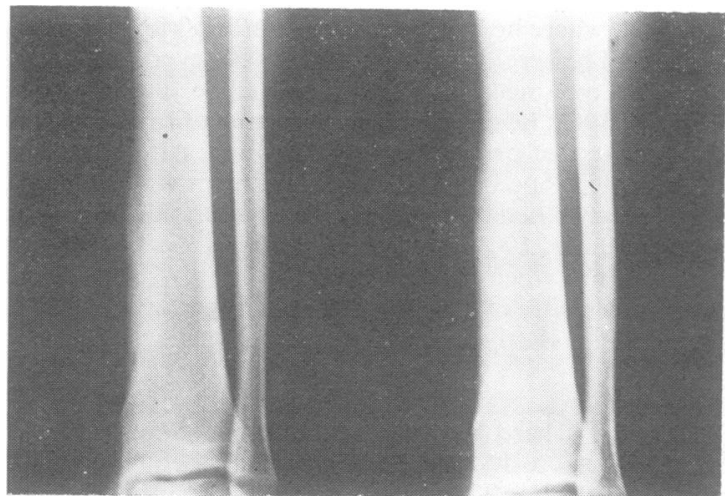

FIG. 4 Case 2. Radiograph of right tibia, showing appearance before (October, 1969) and after (Fanuary. 1970) treatment

foci, and observed that in early syphilis periostitis was more frequently seen than osteolytic lesions. Schwarzkopf and Westerburg (1950) described a case of seropositive primary syphilis with foci of periostitis and small osteolytic lesions in the skull and left sternoclavicular joint. During treatment new focal bony lesions appeared during a classical Herxheimer reaction. $X$-ray evidence of the lesions was still present 2 weeks after the completion of treatment. Thompson and Preston (1952) carried out a radiological survey on a consecutive series of eighty patients with secondary syphilis. Seven cases with osteolytic lesions of the skull were found, and in one of these there was periostitis of the tibiae. Four of these patients complained of headache, and the patient with periostitis had tender red areas on both legs. The authors concluded that asymptomatic osteolytic lesions in early syphilis may be more common than is generally supposed. Greifelt and Bonse (1954) reported a relatively asymptomatic case of 'osteitis and osteomyelitis' of the tibia in early syphilis with almost complete resolution within 3 months after treatment with penicillin. Bauer and Caravati (1967) described a case of secondary syphilis with an osteolytic lesion of the skull. The patient complained of headache, and there was tenderness over the frontal bone; 11 months after treatment $X$ rays showed almost complete resolution.

\section{Case 3. Iritis and papillitis}

A widow aged 47 years, who attended St. Bartholomew's Hospital in March, 1970, had had a febrile illness lasting 2 weeks 3 months previously. After returning to work she had an attack of dizziness followed by pain in the right eye. She was seen at Moorfields Eye Hospital where iritis was diagnosed, and a generalized rash was noted. She was given atropine eye drops and referred to the skin department of St. Bartholomew's, where the results of serological tests for syphilis were reported as: CWR t; VDRL + 1/64; RPCFT +-, FTA-ABS +. She was referred to the Special Clinic, and then gave the additional history of pains in the leg bones for the past 2 months. Her husband had died 6 years previously of mitral stenosis, and she denied having had sexual intercourse since then, in spite of repeated interrogation.

\section{Examination}

There was a sparse papular rash on the face, trunk and feet. The right eye showed ciliary injection, slight irregularity of the pupil, and steamy opacity of the aqueous humour (Fig. 5). The left eye appeared normal. Visual acuity was $6 / 24$ in the right eye, and 6/6 in the left. Treponema pallidum was seen by darkfield examination of scrapings from a papule on the vulva. The erythrocyte sedimentation rate was $52 \mathrm{~mm}$./1st hr. $X$ rays of the leg bones showed no abnormality.

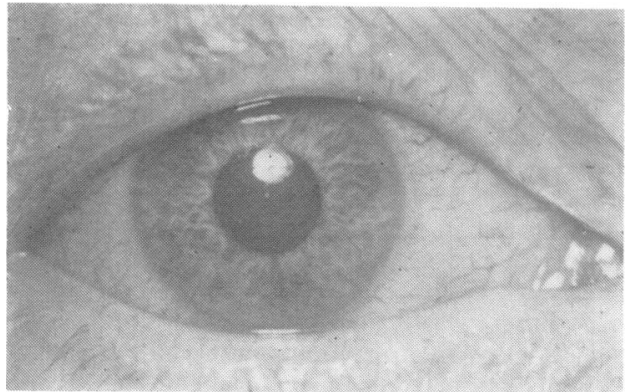

\section{FIG. 5 Case 3. Right eye, showing acute iritis}

A course of penicillin was prescribed, together with potassium iodide $0.3 \mathrm{~g}$. three times a day, orally. The right eye was treated with atropine and topical corticosteroids after a subconjunctival injection of cortisone acetate. There was a transient increase of pain in the tibiae after the first injection of penicillin, but this was followed by rapid relief. By mid-April the ciliary injection had resolved and the aqueous was clear. The right fundus showed marked papillitis (Fig. 6, overleaf), and the left fundus was normal.

When she was last seen in November, 1970, the right fundus still showed some abnormality, but the visual acuity had improved to $6 / 12$. The serological tests for syphilis were still positive but at a very much lower titre (VDRL + 1/2).

\section{Comment}

Iritis usually occurs late in secondary syphilis and 40 years ago it was a complication in 5 to 9 per cent. of cases (Moore, 1931); and papillitis was said to occur in 2.8 per cent. of patients with early syphilis, more frequently in women than men. Before 1935 it was estimated that 30 to 40 per cent. of all cases of iritis in the U.S.A. were due to syphilis (Stokes, Beerman, and Ingraham, 1945). The situation is now radically altered and the percentage in Great Britain is now about 1 to 2 per cent. (Perkins, 1961). Klauder and Dublin (1946), who treated 24 cases of early syphilis with iritis, noted that ocular Herxheimer reactions were frequent; in all but one of their cases the visual acuity returned to normal.

\section{Case 4. Meningitis}

A married man aged 59 years, who attended the Special Clinic in January, 1969, had no symptoms but was concerned because of a casual heterosexual encounter 2 


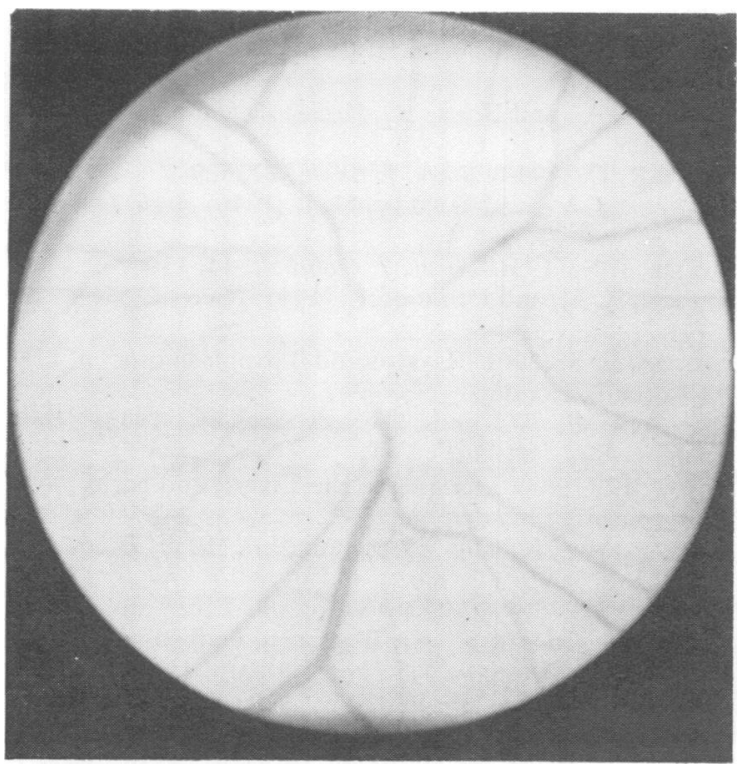

FIG. 6 Case 3. Right fundus, showing papillitis

weeks previously. No clinical abnormalities were found and the serological tests for syphilis were negative, but he was advised to attend for further tests in 3 months' time. When he returned in April, 1969, he was complaining of deafness and stiffness of the knees and ankles of 6 weeks' duration.

\section{Examination}

Some degree of deafness was detected; he was unable to hear a watch ticking, but could hear normal conversation. No abnormality of the joints was found. $X$ rays of the knees, ankles, and sacroiliac joints showed no abnormality except for some calcification in the right Achilles tendon. The erythrocyte sedimentation rate was $42 \mathrm{~mm}$./1st hr., and serological tests for syphilis were reported to be anticomplementary. At this stage it was considered that he might have Reiter's disease, in spite of the absence of any evidence of urethritis. He was referred to the Ear, Nose, and Throat department where both ears were syringed, but this did not affect his deafness. Further serological tests were again said to be anticomplementary, but when these were repeated on April 28, 1970, they gave the following results: CWR + ; RPCFT + ; VDRL + 1/128; FTA-ABS +.

He was now complaining of anorexia and loss of energy. There was no headache or neck stiffness. Examination at this stage showed nerve deafness worse on the right side, and probable early papilloedema of the left optic disc. (Fig. 7).

The visual acuity was $6 / 6$ in both eyes. There was a faint macular rash on the trunk and limbs. Treponema pallidum was seen in darkfield preparations of material taken from a split papule at the corner of the mouth. $\mathrm{He}$ was admitted to hospital for lumbar puncture, and the cerebrospinal fluid was found to be faintly turbid but under normal pressure, with 173 lymphocytes per cu.

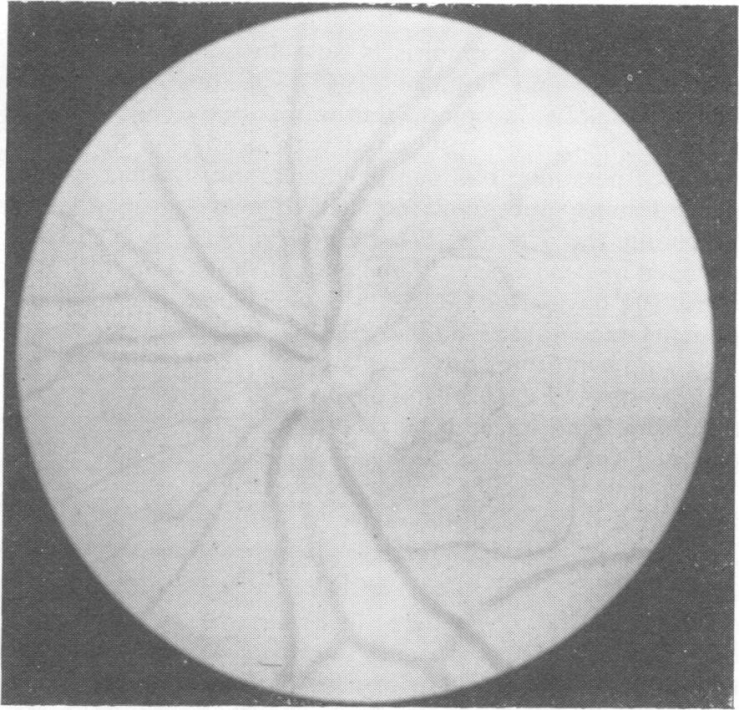

FIG. 7 C'ase 4. Left fundus, shozing papilloedema (May, 1969)

mm., and $45 \mathrm{mg}$. per cent. protein; the Wassermann reaction was positive and the Lange colloidal gold curve showed a 'mid-zone' reaction.

\section{Treatment}

$\mathrm{He}$ was given a course of penicillin continued for 20 days, during which he had a mild Herxheimer reaction. After treatment the VDRL test titre fell to 1 in 32. After discharge from hospital he continued to complain of headache which had started after the lumbar puncture, and also of insomnia and difficulty in concentration. His deafness persisted and audiometry revealed bilateral low and high frequency hearing loss. The high frequency loss was attributed to his service with the Royal Artillery in the second world war, but the low frequency loss was considered to be due to an apical cochlear lesion consistent with treponemal infection. The cerebrospinal fluid was re-examined (in October, 1969) and contained 4 cells per cu. $\mathrm{mm}$. and $49 \mathrm{mg}$. per cent. protein; the Wassermann reaction was negative and the Lange curve nearly normal. Examination of both eyes in December 1969 showed that both discs were of normal appearance.

The patient was able to return to work, but still complained of headache, insomnia, loss of concentration, and faulty memory. The hearing was a little improved in the left ear, but was unchanged in the right. He later developed depressive symptoms but these were relieved by the administration of prothiadine. The serological tests had become negative 20 months after treatment, but his symptoms persisted.

The aetiology of his headaches was not clear; they had persisted too long for a post lumbar puncture headache and in any case were not aggravated by the second puncture. The headache was not relieved by lying down and the patient was normotensive. 


\section{Comment}

Acute syphilitic meningitis is now an uncommon condition. Nelson and Duncan (1945) saw ten cases at the Johns Hopkins Hospital, Baltimore, between 1940 and 1945. Eight of them presented with headache, three had neck stiffness, one had papilloedema, and five had cranial nerve lesions (one involving the 7th nerve only and four involving the 7 th and 8 th nerves). Deafness eventually resolved in every case, but one patient showed no improvement 104 days after the completion of treatment. All the patients except one who had residual facial weakness were free from symptoms one year later. No patient had a completely normal cerebrospinal fluid. The most constant finding was a Lange curve of the 'first-zone' type, but in one case the curve was normal. More recently Wetherill, Webb, and Catterall (1965) described four cases of acute neurological illness due to syphilis. One of the patients, a West Indian male aged 43 years, showed clinical evidence of mengingitis which was confirmed by autopsy.

The case described here illustrates the value of early diagnosis in meningovascular syphilis. There was some avoidable delay in diagnosis because of failure to recognize the rather uncommon presenting signs and symptoms, and earlier treatment might have prevented or lessened the post-meningitic symptoms. The case also shows the value of fundus photography in the assessment of mild degrees of papilloedema.

\section{Summary}

Complications of early syphilis have been uncommon to the point of rarity in Great Britain for over 20 years. Four cases of early syphilis, recently seen at St. Bartholomew's Hospital, London, were associated respectively with hepatitis, periostitis, iritis, and meningitis. The relevant literature is briefly discussed.
References

Bauer, M. F., and Caravati, C. M. (1967) Brit. F. vener. Dis., 43, 175

GreIFELT, A., and BoNSE, G. (1954) Z. Haut-u. Geschlkr., 16, 208

HaHn, R. D. (1943) Amer. F. Syph., 27, 529

KlaUder, J. V., and DuBlin, G. J. (1946) Arch. Ophthal. (Chicago), 35, 384

Moore, J. E. (1931) Amer. J. Ophthal., 14, 110

Nelson, R. A., and Duncan, L. (1945) Amer. F. Syph., 29, 141

Perkins, E. S. (1961) 'Uveitis and Toxoplasmosis', p. 118. Churchill, London

Reynolds, F. W., and WassermanN, H. (1942) Arch. intern. Med., 69, 263

Schiff, L. (1963) 'Diseases of the Liver', 2nd ed., p. 698. Lippincott, Philadelphia

SchWARZKOPF, K., and WESTERBURG, F. (1950) Hautarzt., 1,515

SHERLOCK, S. (1968) 'Diseases of the Liver and Biliary System', 4th ed., p. 607. Blackwell, Oxford

Stokes, J. H., BeERMan, H., and Ingraham, N. R. (1944) 'Modern Clinical Syphilology', 3rd ed., p. 604. Saunders, Philadelphia

Thompson, R. G., and Preston, R. H. (1952) Amer. $\mathcal{F}$. Syph., 36, 332

Wetherill, J. H., WebB, H. E., and Catterali, R. D. (1965) Brit. med. J., i, 1157

Quatre cas inhabituels de syphilis récente SOMMAIRE

Les cas de syphilis récente compliqués sont devenus inhabituels, du fait de leur rareté, en Grande Bretagne depuis plus de 20 ans. A l'Hôpital St. Bartholomew (Londres), il y a peu de temps, quatre cas de syphilis récente ont été observés, auxquels étaient associés, respectivement, une hépatite, une périostite, une iritis et une méningite. La littérature qui se rapporte à la question est brièvement discutée. 